\title{
MATHEMATICS EDUCATIONAL VALUES OF COLLEGE STUDENTS' TOWARDS FUNCTION CONCEPT
}

\author{
Yüksel Dede
}

Received: 24.12.2005, Accepted: 23.01.2006

\begin{abstract}
Mathematics is usually seen as a field in which there is value-free. Such a situation causes only a few studies about values teaching to be done in mathematics education. But, mathematics is a field that has various values in it, and that must be considered seriously from this perspective. Values are taught implicitly rather than explicitly in mathematics classes when comparing to others. Function concept also take place among the most essential concepts of mathematics. It concept has affected the whole maths cirruculum. Therefore, being unable to comprehend this concept will make mathematical concepts understanding harder. Knowledge defiencies of teachers and undergrade students this concept understanding much harder. So, in this article, it has been tried that the mathematics students' mathematics educational values towards function concept have been determined. The subject of this work consist of undergrade students who have studied at Cumhuriyet University in Sivas and also Cumhuriyet University's Mathematics Educational Department in Sivas. Data were collected from 10 open-ended and 11 items reasons of question choose. As a result of this research, it was realized that the students from all grades preferred, in terms of learning the function concept, those questions that hold the formalistic view values, relavance values, instrumental understanding/learning values, accessibility values, and reasoning values.
\end{abstract}

KEYWORDS. Values, Mathematical Values, Mathematics Educational Values, Function Concept.

\section{INTRODUCTION}

Affective aims in courses that are hard to be comprehended by students, like mathematics, should not be neglected. In studies about teaching mathematics'affective field, attitude, belief and motivation dimensions have also been usually taken into consideration and its values teaching dimension is neglected (Seah \& Bishop, 2000). However, values is the most important element of raising mathematics learning and teaching qualities (Seah, 2002). Then, what are values? According to Brown (2001), identifying values is hard. For this, we need some concepts such as "good" and "bad" (Swadener \& Soedjadi, 1988). The word "value" has been used in different meanings. "The value"of unknown in an equation, the "value"of listening a conversation and moral "value" of an individual can be given as an example (Seah \& Bishop, 2000). Swadener and Soedjadi (1988) identify values as a concept or an idea about value of anything. Matthews (2001) also sees them as leaders and means of behaviours. When looking these identifications, it can be described as personel choices considering value or importance of 
a behaviour or idea, or general aims that are adopted or followed by an individual as a member of a society. Therefore values have reflected concepts or ideas about anything. Values can be categorized into two. These are aesthetic and ethical. Aesthetic values are about beauty concepts. Ethical values are about concepts which can be expressed as good or bad and they are interested especially in good and bad sides of a behaviour. This part of values forms a wholeness with education. They cooperate with education and so they make society formation possible (Swadener \& Soedjadi, 1988).

\section{Similarities and Differences among Value, Attitude and Belief}

Terminology used about attitude, belief and value concepts becomes complementary (Bishop et al., 1999). Generally, there is a close relation between values and attitudes. Values have affected emotional components of cognition, emotion and behavior inclination elements of attitudes. And also all of the attitudes has no social side, while values come into existence at two phases as personal and social. Yet, attitudes about social values are social (Tavşanc1l, 2002).

Tavşancıl (2002) describes belief as a whole cognition of an individual about a topic. Thus, values can be seen as a practicing tool of beliefs. (Clarkson et al., 2000). Attitudes and beliefs can undergo some changings as a result of human's experiences during their life. Especially, in adolescence period of individuals, these changes take place much. Yet, we cannot tell the same things about values. Values take root within human souls deeper and they are become more integral by human (Seah, 2003). Values are interested in being important of fact or not being important of fact. For instance, just like a teacher's taking care about using logical thinking, problem solving or technology in accordance with his/her own teaching techniques or vice versa (Seah, 2002). Differences between values and beliefs are given below at table 1 .

Table 1. Possible ways of differentiating beliefs from values

\begin{tabular}{|l|l|l|}
\hline & Belief & Value \\
\hline It is about the degree to which something is & $\ldots$ true & $\ldots$ important \\
\hline It exists... & $\ldots$ in a context & $\ldots$ in the absence of any context \\
\hline
\end{tabular}

(Source: Seah, 2002; Seah \&Bishop, 2002)

Similarities between values and beliefs are also given below at table 2. It provides some examples of beliefs. For each belief, the possible value(s) associated with it is/are suggested. (Seah \& Bishop, 2002). 
Table 2. Examples of beliefs and corresponding values

\begin{tabular}{|l|l|}
\hline Belief & Value(s) \\
\hline Mathematical proofs need to be taught to students. & Rationalism \\
\hline What is important in mathematics has been and will be shown by mathematicians. & Mystery \\
\hline All that matters in mathematics is getting the right answer(s), nevermind the methods used. & Product \\
\hline Mathematics assessment should focus on multiple-choice and short-answer questions. & Product \\
\hline Full marks should be awarded for correct method shown, even if the numerical value is wrong. & Process \\
\hline What is learnt in school mathematics is relevant to life and work. & Relevance \\
\hline The new Maths Methods (CAS) is what school mathematics should be about. & Relevance \\
\hline School mathematics is about understanding and learning ideas. & Concept \\
\hline The role of the mathematics teacher is to teach concepts and demonstrate associated skills. & Authority \\
\hline School mathematics provides us with tools for successful problem-solving. & Tool \\
\hline $\begin{array}{l}\text { As a teacher, I believe that student group work is essential in their mathematics learning } \\
\text { experience. }\end{array}$ & Communication \\
\hline Students in my class are free to work with the manipulatives at any time. & Responsibility \\
\hline
\end{tabular}

(Source: Seah \&Bishop, 2002)

\section{Mathematics and Values}

Modern mathematics has a deductive-axiomatic structure and generally shows a hierachical consruction. So, it is hard to understand a mathematical concept wihout being aware of its preliminary subjects. This deductive-axiomatic structure of mathematics depends on undefined terms, definitions and logical rules (Swadener\& Soedjadi, 1988). Absolutist philosophers; who see mathematics from this perspective, appreciate it as an abstract science and also they think that it is interested in generalization, theory and abstractions. So, mathematics is seen as a field which has no social choice and with which only a few people concerns. And mathematics is value-free; that is to say, it is neutral (Bishop, 1998; Bishop, 2002; Ernest, 1991). In fact, mathematics is loaded with values. It is not neutral. Yet, values are generally taught implicitly rather than explicitly in mathematics. However, values are rarely taken seriously at mathematics educational discussions and mathematics teachers are generally interested in operations that has only one answer. They don't believe values teaching in mathematics lessons (Clarkson et al., 2000). Nowadays, cirruculum programmes are prepared in this way. 
Programmes prepared usually focus on students'achievements. At cirruculum, although there some expressions about values teaching, we meet a little information about their developments. But, it is an obligation that one has more information about values which play a vital role in mathematics educational development (Bishop et al., 2000). They play an important role in students gaining their personal and social identities. Especially, this side of values can be seen at front side in mathematics lessons. Because values affect students' choices about concerning about mathematics or not concerning about it significantly (FitzSimons \& Seah, 2001). Sam and Ernest (1997) classify the values about mathematics education into three such as; i) Epistemological Values: They are the values which are about theoretical side of mathematics learning and teaching such as; accuracy, systematicness, and rationalism and also characteristics, appreciation and acquiring of mathematical knowledge. For example; accuracy, being analytical, rationalism and problem solving. ii) Social and Cultural Values: They are the values that indicate human's responsibilities about mathematics education for society. Such as; compassion, integrity, moderation and gratitude. iii) Personel Values: Values that affect person as an individual or a learner. Such as; curiosity, thriftiness, patience, trust and creativity.

Bishop classifies values taught in mathematics lessons into three different types by making them more specialized than that of Sam and Ernest. These are; general educational values, mathematical values and mathematics educational values (1996; cited in Bishop et al., 1999).

\section{a) General Educational Values}

They are the values which help teachers, schools, culture, society and students to improve. Generally, they contain ethical values such as; good behaviour, integrity, obedience, kindness and modesty (Bishop et al., 1999; FitzSimons et all., 2000). Warning a student who has been cheating during exam can be given as an example for such kind of values (Seah \& Bishop, 2000).

\section{b) Mathematical Values}

Mathematical values are the values that reflect the nature of mathematical knowledge. They are produced by mathematicians who have grown up in different cultures (Bishop et al., 1999). Proving Pythagorean Theorem in three different ways and their appreciation are an example to mathematical values (Seah \&Bishop, 2000). Culture stands as a powerful determiner of mathematical values. Researchs show that basis values of all cultures have not been shared. So, mathematics teachers work in different cultures do not teach the same values, even if they have taught them the same cirruculum (Bishop et al., 2000). Bishop classifies mathematical values taught in Western culture into three categories as complementary of each others (1988; cited in Seah \& Bishop, 2000). These are; 
i) Rationalism-Objectism: Rationality values indicate the values that people have about mathematics. According to this value, mathematics has the ideas which depend on theory, logic and hypothesis (Bishop et al., 2000). Shortly, rationalism value shows a deductive logic which concerns about only correctness of results and explanations. Objectism value shows; because of its nature, objects and symbols which is an instrument to concretize mathematics that has an abstract language (Bishop et al., 1999 ; Seah \& Bishop, 2000).

ii) Control-Progress: Control value shows that mathematics be applied, not only on phenomena about its nature but also on problems, solutions in social areas (Seah \& Bishop, 2000). Mathematics' results have correct answers that can always be controlled (Bishop et al., 1999). However, mathematics with its other aspect is open to progress everytime and it can be used in other fields especially in school lessons,

iii) Openness- Mystery: Openness value shows discussing and analyzing mathematical theorems, ideas, results and argumentations. And such a situation leads us to reach corrects and to find new theorems (Seah \& Bishop, 2000). Mystery value indicates mathematics own relation, pattern and surprises in its own nature. Such as; dividing every circle's perimeter into its diameter gives the same number ( $\pi$ number) or Pythagorean triangles that have $3,4,5$ or $5,12,13 \mathrm{~cm}$ edge lenght gives always a multiple of 60 when they are multiplied with each other. Mathematics has always such kinds of mystery and surprise in itself (Bishop et al., 1999).

Sub-components of mathematical values cited above are fixed by Bishop at table 3;

Table 3. Mathematical values

1.a) Rationalism: Reason, hypotetical reasoning, logical thinking, explanation, abstractions, theories.

1.b) Objectivism: Atomism, materialism, determinism, analogical thinking, objectivising, concretising, symbolising.

2.a) Control: Prediction, knowing, security, mastery over environment, rules, power.

2.b)Progress: Growth, cumulative development of knowledge, generalisation, questioning, alternativism.

3.a) Openness: Facts, articulation, demonstration, verification, universality, individual liberty, sharing.

3.b) Mystery: Abstractness, unclear origins, dehumanised knowledge, wonder, mystique.

(Bishop, 1988; Source: Clarkson et al., 2000)

\section{c) Mathematics Educational Values}

Teaching mathematics educational values may show differences according to countries, cities, school types and grades. For example; choice of problem solving strategies may show differences according to the environment. So, the number of mathematics educational values can increase to that rate. In this paper, five complementary mathematics educational values will be emphasized. The first two of them can be considered as values about pedagogical side of mathematics education and the other three can be considered as values about its cultural side. 
These are;

i) Formalistic view- Activist view: Formalistic view value shows the deductive and receptive learning values of mathematics, while activist view value shows its intuition and discovery learning; that is to say, its inductive sides.

ii) Instrumental understanding/learning-Relational understanding/learning: Instrumental learning indicates learning rules, operations and formulations in mathematics education and their applications to special questions. Relational learning shows displaying the relationships among concepts and forming appropriate graphics.

iii) Relevance - Theoretical knowledge: Relevance value shows the importance of mathematical knowledge in solving daily problems. Daily problems and demands show different at societies and cultures. Thus, mathematics can provide special solutions to cultural needs and demands. Mathematical education's theoretical value suggests teachings mathematics at theoretical basis and far from daily events.

iv) Accessibility -Special: These values indicate doing and preparing mathematical activities by either everyone or just by people who has talent in it.

v) Evaluating - Reasoning: Students are asked to realise the steps of knowing, applying routine operations, searching solving problem, reasoning and communicating in order to solve a problem. The first three of this five steps demonstrate using mathematical knowledge about evaluating an unknown answer; while the last two demonstrate the capability of using mathematical knowledge, reasoning more and the ability of spreading the knowledge (Seah \& Bishop, 2000).

The most general demonstration of values taught in mathematics lesson is given at table 4 below:

Table 4. Values in Mathematics Education

\begin{tabular}{|l|l|l|}
\hline General meanings of 'value' & Mathematical values & Mathematics educational values \\
\hline To value: & Rationalism & Accuracy \\
to command & Objectivism & Clarity \\
to praise & Control & Conjecturing \\
to heed & Progress & Consistency \\
to regard & Mystery & Creativity \\
A value is: & Openness & Effective organization \\
a standard & & Efficient working \\
a thing regarded to have worth \\
$\begin{array}{l}\text { a principle by which we live/act } \\
\text { a standard by which we judge } \\
\text { what is important }\end{array}$ & & Enjoyment \\
something we aim for & & Flexibility \\
qualities to which we conform & & Open mindedness \\
\hline
\end{tabular}

(Source: Seah et al., 2001) 
Values taught in mathematics lessons and values that people, institutes, and societies have are given at figure 1 below:

Figure 1. Relationship of values

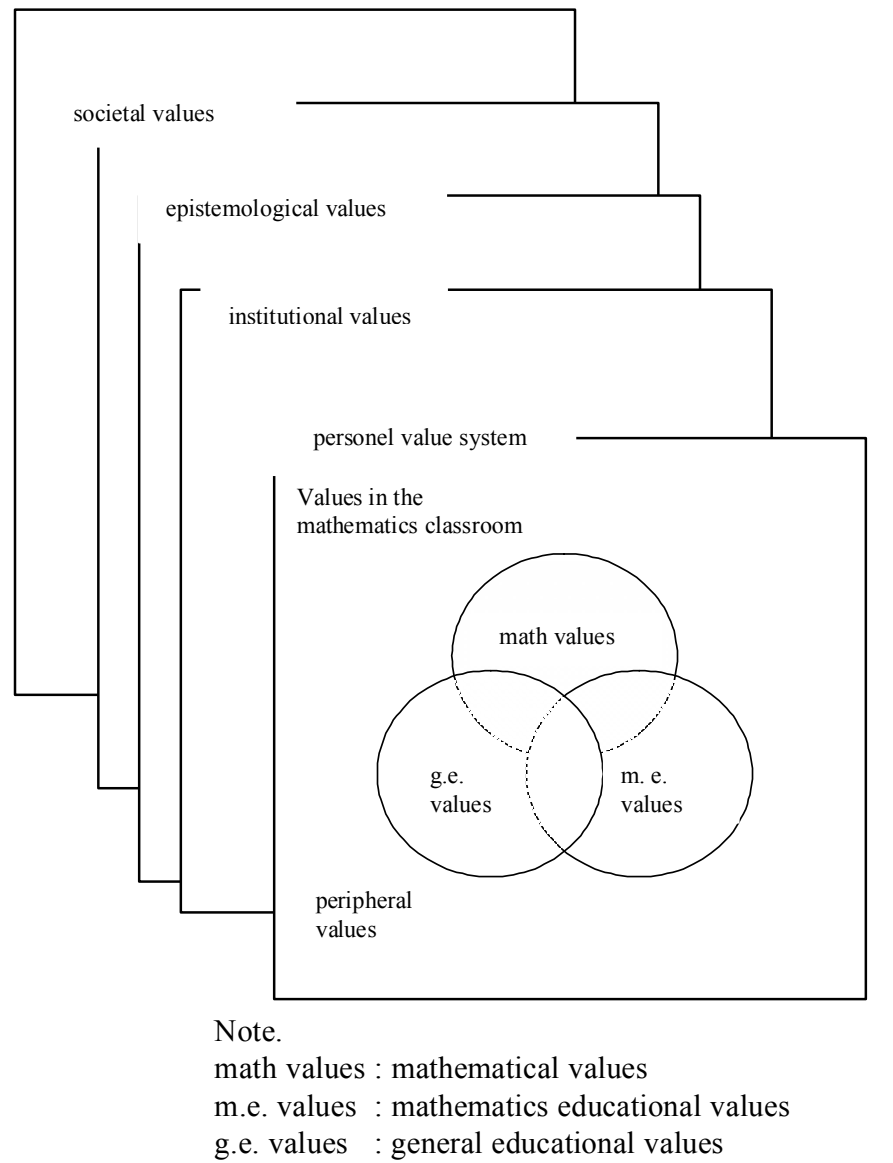

(Source: Seah \& Bishop, 2000)

As will be seen from figure 1, general educational values don't have mathematical and especially mathematics educational values. Some values may appropriate for two or three of these categories. For example; progress and creativity values are both mathematical, mathematics educational and general educational values (Seah \& Bishop, 2000).

Function concept also is one of the most important subjects in mathematics and it affects the whole mathematics curriculum (Beckmann, Thompson \& Senk, 1999; Cooney, 1999; Dossey, 1999; Hitt, 1998; Knuth, 2000; Laughbaum, 2003). However, it seems students have some problems in understanding function concept (Eisenberg, 1991; Even, 1988; Hauge, 1993; Gaea, Orit \& Kay, 1990). One of the reasons of these problems is that definition of function concept has change in historical period. At the beginning, function concept which contains dependent and independent variables was defined by Euler as a procedural concept demonstrating input-output relations and then as a concept representing one to one matching 
between real numbers by Dirichlet (Kieran, 1992; Stallings, 2000) and a century later as a certain subset of Cartesian product by Bourbaki in 1939 (1986; cited in Kleiner, 1989) as followings:

Let $E$ and $F$ be two sets, which may or may not be distinct. A relation between a variable element $x$ of $E$ and a variable element $y$ of $F$ is called a functional relation in $y$ if, for all there exists a unique which is in the given relation with $x$. We give the name of function to the operation which in this way associates with every element the element which is in the given relation with $x$; $y$ is said to be the value of the function at the element $x$, and the function is said to be determined by the given functional relation. Two equivalent functional relations determine the same function (p.298).

As it can be seen in above definition, definition of function concept is considered as a set of ordered pair. In 1960's, by "new mathematics" reform frame, it was tried to make definitions of mathematics concepts more clear, making them comprehensible for students. Definition of function concept was given as following (Tall,1992):

Let $A$ and $B$ be sets, and let $A X B$ denote the Cartesian product of $A$ and $B . A$ subset $f$ of $A X B$ is a function if, whenever $\left(x_{1}, y_{1}\right)$ and $\left(x_{2}, y_{2}\right)$ are elements of $f, x_{1}=x_{2}$ and $y_{1}=y_{2}$, then (p. 497).

By this way, in contrast to past times, the definition was not limited to equations which define relationships between two variables in algebraic expressions. (Even, 1988). However, this modern definition did not meet expectations either, as a matter of fact it sometimes caused to students not to understand the concept. For, although this modern definition of 1960's has a perfect mathematical base, it does not have a cognitive origin (Tall, 1992). At this point, below statements of Sierpinska (1988; cited in Tall, 1992) attract attentions:

The most fundamental conception of a function is that of a relationship between variable magnitudes. If this is not developed, representations such as equations and graphs lose their meaning and become isolated from one another... Introducing functions to young students by their elaborate modern definition is a didactical error an anti-didactical inversion (p. 497)

It has been seen that the problem that students have in comprehending function concept arises from ideas which individuals develop about mathematical concepts rather than the words used in definitions (Tall,1992). At this point, it seems that there exists differences between a formal concept definition and a concept image and this differentiation is conveyed by Tall \&Vinner (1981) as below:

... the term concept image to describe the total cognitive structure that is associated with the concept, which includes all the mental pictures and associated properties and processes. It is built up over the years through experiences of all kinds, changing as the individual meets new stimuli and matures... The definition of a concept (if it has one) is quite a different matter...the concept definition to be a form of words used to specify that concept. It may be learnt by an individual in a rote fashion or more meaningfully learnt and related to a greater or lesser degree to the concept as a whole. It may also be a personal reconstruction by the student of a definition (p. 152). 
As it can be concluded from above statements, giving a definition of a concept to students is not enough for them to comprehend it. This is especially valid for the function concept since the function concept have been represented as geometric using graphs, numeric using tables, and symbolic using equations. Namely, it is multiply represented (DeMarois\& Tall, 1996). This case makes it difficult for students to comprehend the function concept. In addition, the fact that functions have many kinds such as polynomial (as constant, linear, quadratic, cubic), trigonometric and reciprocal etc is one of the factors that make the function concept hard to perceive.

One of the reasons why students do not understand the concept of function well is the fact that the mathematical values tought to students through curriculum textbooks, teachers etc. during the teaching of this concept are overlooked for instance, the teaching of functions through graphics and tables contains the activist value of the teaching of mathematics whereas their symbolic representation contains its rationalism value. Likewise, while questions such as "is every function an equation? Is the opposite true? Contains relational understanding/learning value related to the teaching of functions. A question related as " $f(x)=3 x+1$ is given defined in $R$. What is $f(1)=$ ? " Contains both instrumental understanding/learning value and accessibility value. In this respect the prominence of determining which educational values of the function concept mentioned above are brought forth is understood.

And therefore in this research, it has been searched that how much do mathematics educational values take place in the function concept teaching. For this purpose, the answer for questions below have been looked for;

1) For what mathematical education values towards the function concept do students qualify more?

a) Do the mathematical education values towards the function concept, which the students own, indicate a remarkable variation according to the grade levels of college students?

2) Does the students' rationality for choosing the questions on the Function's Test change according to the grade levels of college students?

\section{METHODOLOGY}

\section{Subjects}

The subjects for this study consist of three hundred and forty three students. The students count approximately seventy-seven, hundered and eight, seventy-five, and eighty-three. They are the first, second, third, and fourth-year students from the Primary Mathematics Education at Cumhuriyet University (CPME). The ages of these students change approximately between 17 and 25. The university also has a thirty-year old campus in Sivas, a province of the Turkish Republic in Central Anatolia. 


\section{Apparatus}

In order to determine students' mathematics educational values towards the function concept, the students were given two tests. One was "the Function Test" that included ten openended questions. The students were asked to answer for five of the ten questions asked in total. Each of the questions in the test are organized according to consisting of the one of mathematical educational values mentioned above such as formalistic view value, activist view value etc. The other was "the Rationality Test" that asked the reasons for their choosing of particular questions to respond on the Function Test. The test consisted of the some choose items adapted from the research done Chin and Lin (2000). The answered questions were evaluated as one point and the blanks as nil.

The following four questions illustrate the questions given to the students on the test:

1. Graph the $f(x)=x^{2}$ and do the graphics of the functions below using this function. (This question intended to determine the students' formalistic view value)

$$
\begin{array}{ll}
\text { i) } g(x)=x^{2}+3 & \text { ii) } k(x)=x^{2}-\sqrt{3}
\end{array}
$$

4) The distribution of the number of the bus tickets sold to the students in the province of Sivas in the year 1998 is given in the table below. (The Municipality Activity Report of Sivas, 1998)

a) Graph this statistical information.

b) Is the function in the graphic one-to-one? And why? (This question intended to determine the students' relevance value)

\begin{tabular}{|c|c|c|c|c|c|c|c|c|c|c|c|c|}
\hline Month & January & February & March & April & May & June & July & August & September & October & November & December \\
\hline $\begin{array}{l}\text { The number } \\
\text { of tickets } \\
\text { sold to the } \\
\text { students }\end{array}$ & 238.800 & 325.525 & 340.495 & 314.100 & 343.400 & 351.500 & 269.500 & 213.300 & 325.500 & 347.800 & 322.700 & 326.000 \\
\hline
\end{tabular}

6) i) Is every function a relation? Discuss your answer.

ii) Is every relation a function? Discuss your answer. (This question intended to determine the students' relational understanding/learning)

7) A function of is given defined in. What is (This question intended to determine the students'accessibilty value) 


\section{FINDINGS AND CONCLUSIONS}

Research findings will be given in light of the research questions.

Question 1: For what mathematical education values towards the function concept do students qualify more?

a) Do the mathematical education values towards the function concept, which the students own, indicate a remarkable variation according to the grade levels of college students?

Table 5. Choose of questions in function test

\begin{tabular}{|c|c|c|c|c|c|c|c|c|}
\hline \multirow{2}{*}{$\begin{array}{l}\text { Question } \\
\text { Number }\end{array}$} & \multicolumn{2}{|c|}{ First Class } & \multicolumn{2}{|c|}{ Secondary Class } & \multicolumn{2}{|c|}{ ThirdClass } & \multicolumn{2}{|c|}{ Fourth Class } \\
\hline & $\mathrm{n}$ & $\%$ & $\mathrm{n}$ & $\%$ & $\mathrm{n}$ & $\%$ & $\mathrm{n}$ & $\%$ \\
\hline 1 & 52 & 67,5 & 99 & 91,7 & 72 & 96,0 & 71 & 85,5 \\
\hline 2 & 18 & 23,4 & 32 & 29,6 & 27 & 36,0 & 25 & 30,1 \\
\hline 3 & 6 & 7,8 & 5 & 4,6 & 18 & 24,0 & 9 & 10,8 \\
\hline 4 & 16 & 20,8 & 40 & 37,0 & 26 & 34,7 & 33 & 39,8 \\
\hline 5 & 76 & 98,7 & 104 & 96,3 & 73 & 97,3 & 77 & 92,8 \\
\hline 6 & 39 & 50,6 & 34 & 31,5 & 28 & 37,3 & 36 & 43,4 \\
\hline 7 & 66 & 85,7 & 97 & 89,8 & 63 & 84,0 & 79 & 95,2 \\
\hline 8 & - & - & - & - & - & - & - & - \\
\hline 9 & 60 & 77,9 & 59 & 54,6 & 25 & 33,3 & 36 & 43,4 \\
\hline 10 & 49 & 63,6 & 70 & 64,8 & 39 & 52,0 & 47 & 56,6 \\
\hline
\end{tabular}

The first question demonstrates the abstracting nature of math education and the value of formalistic view. The second question displays the activist view value of math education. On the other hand, it was designated that the class level of students has a meaningful impact on the selection of the first question $(\mathrm{F}(3-334)=14.163, \mathrm{p}<.05)$. According to the results of the Sheffe's test, which was conducted to determine in what groups the interclass differences are, the second-year $(\bar{x}=.92)$, third-year $(\bar{x}=.97)$, and fourth-year students $(\bar{x}=.90)$ responded to the first question in greater number than the first-year students $(\bar{x}=.66)$. This statistical data points to that the second and higher-year students go for the formalistic view value in math education. Then, this situation can be explained by the fact that the higher-year the students are, the more absract courses they take. On the other hand, it was designated that the class level of students does not have a meaningful impact on the selection of the second question $(\mathrm{F}(3-334)=1.448, \mathrm{p}>.05)$. 
It has been seen from the Table 5 that the first greaders' sixty-seven point five (67.5) percent answered the first question and their twenty-three point four (23.4) percent answered the second. It has also been understood from the table that the second, third, and fourth-year students responded to the first question in greater numbers than to the second question. This situation acquaint with the fact that every student regardless of their class level has preferred the formalistic view value in math education more when compared to the active view value.

While the third question demonstrates the theoretical value in math education, the fourth question attributes to the relevance value. It was designated that the class level of students has a meaningful impact on the selection of the third question $(\mathrm{F}(3-339)=6.98, \mathrm{p}<.05)$. According to the results of the Sheffe's test, which was conducted to determine in what groups the interclass differences are, a meaningful difference is observed in advantage of the third-year students among the first $(\bar{x}=.007)$, second $(\bar{x}=.003)$, and third-year students $(\bar{x}=.24)$ in terms of selecting the third question. In addition, the level of class has a meaningful impact on the selection of the fourth question $(\mathrm{F}(3-337)=2.872, \mathrm{p}<.05)$. According to the results of the Tukey's test, which was conducted to determine in what groups the interclass differences are, a meaningful difference is observed in advantage of the fourth-year students between the first $(\bar{x}=.19)$ and fourth-year students $(\bar{x}=.40)$ in terms of selecting the fourth question. It can be argued that the difference between the two levels have resulted from the fact that the fourth-year students have practiced during the courses on Special Teaching Methods the activities concerning the abstraction in math teaching and its connection with the daily life.

It is observed from the Table 5 that every student regardless of their class-level responded to the fourth question in greater numbers than to the third question. This situation leads to the fact that all the students have preferred the question having the relevance value in math education more when compared to the question having the theoretical value.

While the fifth question indicates a process of the instrumental understanding/learning value, the sixth question signifies the relational understanding/learning value in math education.

It is designated that the class-level of students had a meaningful impact on the selection of the fifth question $(\mathrm{F}(3-336)=2.80, \mathrm{p}<.05)$. According to the results of the Tukey's test, which was conducted to determine in what groups the interclass differences are, a meaningful difference is observed in advantage of the third-year students between the third $(\bar{x}=.97)$ and fourth-year students $(\bar{x}=.93)$ in terms of having answered the fifth question. Whereas the classlevel did not have a meaningful impact on the preference to answer the sixth question $(\mathrm{F}(3-339)=2.53, \mathrm{p}>.05)$, all the students responded from the Table 5 to the fifth question in greater number than to the sixth question. This situation points to the fact that every student regarless of his or her class-level prefers the question having a process of the instrumental understanding/learning value more when compared to the question having the relational understanding/learning value in math education. 
While the seventh question refers to the accessibility value, the eighth question demonstrates the special value in math education. It has been designated that the class-level of students did not have a meaningful impact on the preference for the seventh question (F (3-339) $=2.02, \mathrm{p}>.05)$. In addition, no student responded to the eigth question. This situation leads to the fact that every student regardless of his or her class-level prefers the question having the accessibility value more when compared to the question having the specialty value in math education.

While the ninth question illustrates the reasoning value, the tenth question signifies the evaluating value in math education. It has been observed that the class-level of students has a meaningful impact on the selection of the ninth question $(\mathrm{F}(3-339)=12.42, \mathrm{p}<.05)$. According to the results of the Sheffe's test, which was conducted to determine in what groups the interclass differences are, a meaningful difference has been found in advantage of the first-year students among the first $(\bar{x}=.78)$, second $(\bar{x}=.55)$, third $(\bar{x}=.33)$, and fourth- year students $(\bar{x}=.43)$ in terms of having answered the ninth question. Furthermore, a meaningful difference has been discovered in advantage of the second-year students between the second and third-year students. The selection of this question by the first-year students can be explained by the fact that the firstyear students learned the notion of function in various lessons based on the first-year curriculum. It has also been observed that the class-level does not have a meaningful impact on the selection of the tenth question $(\mathrm{F}(3-339)=1.28, \mathrm{p}>.05)$.

Table 6. Reasons of choose of question 1 and 2

\begin{tabular}{|c|c|c|c|c|c|c|c|c|c|c|c|c|c|c|c|c|}
\hline \multirow{3}{*}{ Choose } & \multicolumn{4}{|c|}{ First class } & \multicolumn{4}{|c|}{ Secondary class } & \multicolumn{4}{|c|}{ Third class } & \multicolumn{4}{|c|}{ Fourth class } \\
\hline & \multicolumn{2}{|c|}{ Question 1} & \multicolumn{2}{|c|}{ Question 2} & \multicolumn{2}{|c|}{ Question 1 } & \multicolumn{2}{|c|}{ Question 2} & \multicolumn{2}{|c|}{ Question 1} & \multicolumn{2}{|c|}{ Question 2} & \multicolumn{2}{|c|}{ Question 1 } & \multicolumn{2}{|c|}{ Question 2 } \\
\hline & $\mathbf{n}$ & $\%$ & $\bar{n}$ & $\%$ & $\bar{n}$ & $\%$ & $\bar{n}$ & $\%$ & $\bar{n}$ & $\%$ & $\bar{n}$ & $\%$ & $\bar{n}$ & $\%$ & $\bar{n}$ & $\%$ \\
\hline it had a logic of induction & - & - & & & 12 & 11,2 & 2 & 1,9 & 2 & 2,7 & - & - & 16 & 19,3 & & \\
\hline it had a logic of deduction & - & - & 5 & 6,5 & 1 & 0,9 & 13 & 12,0 & 1 & 1,3 & 7 & 9,3 & - & - & 19 & 22,9 \\
\hline it is related to daily life & - & - & - & - & - & - & 1 & 0,9 & - & & 2 & 2,7 & - & - & 1 & 1,2 \\
\hline $\begin{array}{l}\text { it only addresses to the } \\
\text { theory }\end{array}$ & 3 & 3,9 & - & - & 4 & 4,7 & & & 3 & 4,0 & 1 & 1,3 & 6 & 7,2 & - & - \\
\hline $\begin{array}{l}\text { it gave the opportunity to } \\
\text { use the rules, operation, } \\
\text { and formulas }\end{array}$ & 10 & 13,0 & 1 & 1,3 & 8 & 7,4 & 3 & 2,8 & 8 & 10,7 & 1 & 1,3 & 8 & 9,6 & 1 & 1,2 \\
\hline $\begin{array}{l}\text { it shows tha conceptual } \\
\text { relations }\end{array}$ & 3 & 3,9 & - & - & 10 & 9,3 & & & 4 & 5,3 & 2 & 2,7 & 5 & 6,0 & 2 & 2,4 \\
\hline it was so easy & 10 & 13,0 & 2 & 2,6 & 10 & 9,3 & & & 11 & 14,7 & 2 & 2,7 & 6 & 7,2 & 1 & 1,2 \\
\hline $\begin{array}{l}\text { it was a question that only } \\
\text { those having the } \\
\text { mathematical knowledge } \\
\text { and skills could answer }\end{array}$ & 3 & 3,9 & 3 & 3,9 & 11 & 10,2 & 4 & 3,7 & 7 & 9,3 & 5 & 6,7 & 6 & 7,2 & & \\
\hline it looked familiar & 19 & 24,7 & 3 & 3,9 & 36 & 33,3 & 3 & 2,8 & 30 & 40,0 & 1 & 1,3 & 20 & 24,1 & 2 & 2,4 \\
\hline $\begin{array}{l}\text { the question let me make } \\
\text { revisions on it }\end{array}$ & 2 & 2,6 & 1 & 1,3 & 1 & 0,9 & 1 & 0,9 & & & & & 2 & 2,4 & - & - \\
\hline Other reasons & 2 & 2,6 & 2 & 2,6 & 6 & 5,6 & - & - & 4 & 5,3 & 4 & 5,3 & 2 & 2,4 & - & - \\
\hline
\end{tabular}


It has been seen from the Table 5 that all the second, third, and fourth-year students but the first-year students responded to the tenth question in greater numbers than to the ninth question. This situation concludes that all the students except the first-year students has preferred the question having the reasoning value to the questions having the evaluating value in math education.

Question 2: Does the students' rationality for choosing the questions on the Function's Test change according to the grade levels of college students?

The Table 6 has given the reasons for why the students chose the first and second questions in the Function Test. Here, it has been observed that the first-year students answered not the first alternative of the first and second questions but the ninth alternative of the first question by a twenty-four point seven (24.7) percent and the second alternative of the second question by a six point five (6.5) percent. As for others; the second-year students answered the first question for its ninth alternative by a thirty-three point three (33.3) percent and the second question for its second alternative by a twelve (12) percent, the third-year students answered the first question for its ninth alternative by a forty (40) percent and the second question for its second alternative by a nine point three (9.3) percent, and the fourth-year students answered the first question for its ninth alternative by a twenty-four point one (24.1) percent and the second question for its second alternative by a twenty-two point nine (22.9) percent.

Table 7. Reasons of choose of question 3 and 4

\begin{tabular}{|c|c|c|c|c|c|c|c|c|c|c|c|c|c|c|c|c|}
\hline \multirow{3}{*}{ Choose } & \multicolumn{4}{|c|}{ First class } & \multicolumn{4}{|c|}{ Secondary class } & \multicolumn{4}{|c|}{ Third class } & \multicolumn{4}{|c|}{ Fourth class } \\
\hline & \multicolumn{2}{|c|}{ Question 3 } & \multicolumn{2}{|c|}{ Question 4} & \multicolumn{2}{|c|}{ Question 3 } & \multicolumn{2}{|c|}{ Question 4} & \multicolumn{2}{|c|}{ Question 3 } & \multicolumn{2}{|c|}{ Question 4} & \multicolumn{2}{|c|}{ Question 3 } & \multicolumn{2}{|c|}{ Question 4} \\
\hline & $\mathbf{n}$ & $\%$ & $\mathbf{n}$ & $\%$ & $\mathbf{n}$ & $\%$ & $\bar{n}$ & $\%$ & $\mathbf{n}$ & $\%$ & $\bar{n}$ & $\%$ & $\bar{n}$ & $\%$ & $\mathbf{n}$ & $\%$ \\
\hline it had a logic of induction & - & - & - & - & 1 & 0,9 & - & - & - & - & - & - & 1 & 1,2 & & \\
\hline it had a logic of deduction & - & - & - & - & - & - & 1 & 0,9 & 1 & 1,3 & - & - & - & - & 1 & 1,2 \\
\hline it is related to daily life & - & - & 7 & 9,1 & 3 & 2,8 & 17 & 15,7 & & & 14 & 18,7 & 1 & 1,2 & 20 & 24,1 \\
\hline $\begin{array}{l}\text { it only addresses to the } \\
\text { theory }\end{array}$ & - & - & & & 1 & 0,9 & 2 & 1,9 & 1 & 1,3 & & & 5 & 6,0 & 1 & 1,2 \\
\hline $\begin{array}{l}\text { it gave the opportunity to } \\
\text { use the rules, operation, } \\
\text { and formulas }\end{array}$ & 1 & 1,3 & 1 & 1,3 & 1 & 0,9 & 5 & 4,6 & 2 & 2,7 & 1 & 1,3 & - & - & & \\
\hline $\begin{array}{l}\text { it shows tha conceptual } \\
\text { relations }\end{array}$ & 1 & 1,3 & - & - & - & - & 5 & 4,6 & 2 & 2,7 & 5 & 6,7 & - & - & 2 & 2,4 \\
\hline it was so easy & - & - & 2 & 2,6 & - & - & 3 & 2,8 & 1 & 1,3 & - & - & - & - & & \\
\hline $\begin{array}{l}\text { it was a question that only } \\
\text { those having the } \\
\text { mathematical knowledge } \\
\text { and skills could answer }\end{array}$ & - & - & 1 & 1,3 & 1 & 0,9 & - & - & 2 & 2,7 & 1 & 1,3 & 1 & 1,2 & 2 & 2,4 \\
\hline it looked familiar & 2 & 2,6 & 2 & 2,6 & - & - & 3 & 2,8 & 4 & 5,3 & & & 1 & 1,2 & & \\
\hline $\begin{array}{l}\text { the question let me make } \\
\text { revisions on it }\end{array}$ & 1 & 1,3 & 1 & 1,3 & - & - & 1 & 0,9 & & & 1 & 1,3 & - & - & 1 & 1,2 \\
\hline Other reasons & - & - & & - & - & - & - & - & 1 & 1,3 & 1 & 1,3 & - & - & 3 & 3,6 \\
\hline
\end{tabular}


When the statistical data given above is analyzed, it is observed that the reasons of the students from all grades for choosing the first and second question appear in an order to be as "because it looked familiar" and "because it had the logic of induction." In fact, this situation is an expected result. Indeed, the first question might have looked familiar to the students because the lessons that the students from all grades took or are taking teach the abstract way of mathematics. Moreover, the students may well have responded to the second question having the logic of induction because they have been familiar with the methods of induction and deduction.

The Table 7 has given the reasons for why the third and fourth questions were chosen by the students. When the statistical data here is analyzed, it is observed that the reasons of the students from all grades for responding to the third and fourth questions appear to be as "because they are related to the daily life." This situation is an expected result for the fourth question. Indeed, the data for the fourth question was derived from the real life. But the data for the third question appeals to the theoretical aspect of math education. For this reason, it had been anticipated that the students would prefer this question merely because "it addressed to the theory."

Table 8. Reasons of choose of question 5 and 6

\begin{tabular}{|c|c|c|c|c|c|c|c|c|c|c|c|c|c|c|c|c|}
\hline \multirow[t]{3}{*}{ Choose } & \multicolumn{4}{|c|}{ First class } & \multicolumn{4}{|c|}{ Secondary class } & \multicolumn{4}{|c|}{ Third class } & \multicolumn{4}{|c|}{ Fourth class } \\
\hline & \multicolumn{2}{|c|}{ Question 5 } & \multicolumn{2}{|c|}{ Question 6 } & \multicolumn{2}{|c|}{ Question 5 } & \multicolumn{2}{|c|}{ Question 6 } & \multicolumn{2}{|c|}{ Question 5 } & \multicolumn{2}{|c|}{ Question 6 } & \multicolumn{2}{|c|}{ Question 5 } & \multicolumn{2}{|c|}{ Question 6 } \\
\hline & $\mathbf{n}$ & $\%$ & $\mathbf{n}$ & $\%$ & $\mathbf{n}$ & $\%$ & $\mathbf{n}$ & $\%$ & $\mathbf{n}$ & $\%$ & $\mathbf{n}$ & $\%$ & $\mathbf{n}$ & $\%$ & $\mathbf{n}$ & $\%$ \\
\hline it had a logic of induction & 1 & 1,3 & 1 & 1,3 & - & - & - & - & - & - & 1 & 1,3 & - & - & 1 & 1,2 \\
\hline it had a logic of deduction & - & - & - & - & & & 1 & 0,9 & 2 & 2,7 & - & - & 2 & 2,4 & 1 & 1,2 \\
\hline it is related to daily life & - & - & - & - & & & 1 & 0,9 & 1 & 1,3 & - & - & - & - & - & - \\
\hline $\begin{array}{l}\text { it only addresses to the } \\
\text { theory }\end{array}$ & 3 & 3,9 & 11 & 14,3 & 6 & 5,6 & 6 & 5,6 & 1 & 1,3 & - & - & 3 & 3,6 & 3 & 3,6 \\
\hline $\begin{array}{l}\text { it gave the opportunity to } \\
\text { use the rules, operation, } \\
\text { and formulas }\end{array}$ & 26 & 33,8 & 2 & 2,6 & 60 & 55,6 & - & - & 27 & 36,0 & - & - & 34 & 41,0 & - & - \\
\hline $\begin{array}{l}\text { it shows tha conceptual } \\
\text { relations }\end{array}$ & - & - & 7 & 9,1 & 1 & 0,9 & 20 & 18,5 & 1 & 1,3 & 13 & 17,3 & 3 & 3,6 & 14 & 16,9 \\
\hline it was so easy & 25 & 32,5 & 1 & 1,3 & 14 & 13,0 & & & 15 & 20,0 & 2 & 2,7 & 11 & 13,3 & 3 & 3,6 \\
\hline $\begin{array}{l}\text { it was a question that only } \\
\text { those having the } \\
\text { mathematical knowledge } \\
\text { and skills could answer }\end{array}$ & 2 & 2,6 & 4 & 5,2 & 5 & 4,6 & 3 & 2,8 & 7 & 9,3 & 4 & 5,3 & 7 & 8,4 & 6 & 7,2 \\
\hline it looked familiar & 17 & 22,1 & 10 & 13,0 & 11 & 10,2 & 3 & 2,8 & 12 & 16,0 & 6 & 8,0 & 10 & 12,0 & 4 & 4,8 \\
\hline $\begin{array}{l}\text { the question let me make } \\
\text { revisions on it }\end{array}$ & 1 & 1,3 & 1 & 1,3 & 2 & 1,9 & & & 2 & 2,7 & 2 & 2,7 & 2 & 2,4 & & \\
\hline Other reasons & - & - & - & - & - & - & 3 & 2,8 & 1 & 1,3 & - & - & - & - & 1 & 1,2 \\
\hline
\end{tabular}

The Table 8 has given the reasons for why the fifth and sixth questions in the Function Test were chosen by the students. When the data here is analyzed, it is observed that the reasons of the students from all grades to have answered the fifth question happen to be as "because it 
provided the opportunity to use the rules, operation, and formulas." This situation is an expected result for the fifth question. Indeed, this question asked to inverse a function and then to calculate the resultants of this inversed function with another. It is also observed that the students from all grades responded to the sixth question mostly because "it proved the relations among the concepts." This situation is an expected result for the sixth question too. Indeed, this question explores into the connection between the function and relation concepts.

Table 9. Reasons of choose of question 7 and 8

\begin{tabular}{|c|c|c|c|c|c|c|c|c|c|c|c|c|c|c|c|c|}
\hline \multirow{3}{*}{ Choose } & \multicolumn{4}{|c|}{ First class } & \multicolumn{4}{|c|}{ Secondary class } & \multicolumn{4}{|c|}{ Third class } & \multicolumn{4}{|c|}{ Fourth class } \\
\hline & \multicolumn{2}{|c|}{ Question 7 } & \multicolumn{2}{|c|}{ Question 8} & \multicolumn{2}{|c|}{ Question 7 } & \multicolumn{2}{|c|}{ Question 8 } & \multicolumn{2}{|c|}{ Question 7} & \multicolumn{2}{|c|}{ Question 8} & \multicolumn{2}{|c|}{ Question 7 } & \multicolumn{2}{|c|}{ Question 8} \\
\hline & $\mathbf{n}$ & $\%$ & $\mathbf{n}$ & $\%$ & $\mathbf{n}$ & $\%$ & $\mathbf{n}$ & $\%$ & $\mathbf{n}$ & $\%$ & $\mathbf{n}$ & $\%$ & $\mathbf{n}$ & $\%$ & $\mathbf{n}$ & $\%$ \\
\hline it had a logic of induction & - & - & - & - & & & - & - & & & - & - & & & - & - \\
\hline it had a logic of deduction & - & - & - & - & & & - & - & & & - & - & & & - & - \\
\hline it is related to daily life & - & - & - & - & & & - & - & 1 & 1,3 & - & - & & & - & - \\
\hline it only addresses to the theory & 1 & 1,3 & - & - & 1 & 0,9 & - & - & 2 & 2,7 & - & - & 1 & 1,2 & - & - \\
\hline $\begin{array}{l}\text { it gave the opportunity to use } \\
\text { the rules, operation, and } \\
\text { formulas }\end{array}$ & 4 & 5,2 & - & - & 9 & 8,3 & - & - & 5 & 6,7 & - & - & 3 & 3,6 & - & - \\
\hline $\begin{array}{l}\text { it shows tha conceptual } \\
\text { relations }\end{array}$ & & & - & - & 83 & 76,8 & - & - & & & - & - & 1 & 1,2 & - & - \\
\hline it was so easy & 60 & 77,9 & - & - & & & - & - & 52 & 69,3 & - & - & 68 & 81,9 & - & - \\
\hline $\begin{array}{l}\text { it was a question that only } \\
\text { those having the } \\
\text { mathematical knowledge and } \\
\text { skills could answer }\end{array}$ & - & - & - & - & & & - & - & 1 & 1,3 & - & - & & & - & - \\
\hline it looked familiar & 3 & 3,9 & - & - & 2 & 1,9 & - & - & 4 & 5,3 & - & - & 2 & 2,4 & - & - \\
\hline $\begin{array}{l}\text { the question let me make } \\
\text { revisions on it }\end{array}$ & & & - & - & & & - & - & & & - & - & & & - & - \\
\hline Other reasons & & & - & - & & & - & - & & & - & - & & & - & - \\
\hline
\end{tabular}

The Table 9 has given the reasons of the students for choosing the seventh and eight questions. When the data here is analyzed, the reasons of the students from all grades for responding to the seventh question appear to be as mostly "because they were very easy." This situation is an expected result for the seventh question. Indeed, this question is a question the answer of which is easy and it demonstrates the accessibilty value in maths. But the eighth question requires a higher-level knowledge in the function concept. It is observed from the Table 8 that this question was not preferred or answered by any student. 
Table 10. Reasons of choose of question 9 and 10

\begin{tabular}{|c|c|c|c|c|c|c|c|c|c|c|c|c|c|c|c|c|}
\hline \multirow[t]{3}{*}{ Choose } & \multicolumn{4}{|c|}{ First class } & \multicolumn{4}{|c|}{ Secondary class } & \multicolumn{4}{|c|}{ Third class } & \multicolumn{4}{|c|}{ Fourth class } \\
\hline & \multicolumn{2}{|c|}{ Question 9 } & \multicolumn{2}{|c|}{ Question 10 } & \multicolumn{2}{|c|}{ Question 9 } & \multicolumn{2}{|c|}{ Question 10 } & \multicolumn{2}{|c|}{\begin{tabular}{|l|} 
Question 9 \\
\end{tabular}} & \multicolumn{2}{|c|}{ Question 10 } & \multicolumn{2}{|c|}{ Question 9 } & \multicolumn{2}{|c|}{ Question 10 } \\
\hline & $\mathbf{n}$ & $\%$ & $\bar{n}$ & $\%$ & $\bar{n}$ & $\%$ & $\bar{n}$ & $\%$ & $\mathbf{n}$ & $\%$ & $\bar{n}$ & $\%$ & 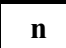 & $\%$ & 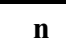 & $\%$ \\
\hline it had a logic of induction & - & - & - & - & 2 & 1,9 & 2 & 1,9 & - & - & - & - & 1 & 3,1 & 3 & 3,6 \\
\hline it had a logic of deduction & - & - & - & - & 1 & 0,9 & & & - & - & - & - & & & 1 & 1,2 \\
\hline it is related to daily life & - & - & - & - & 2 & 1,9 & 1 & 0,9 & - & - & - & - & & & & \\
\hline it only addresses to the theory & 8 & 10,4 & 4 & 5,2 & 10 & 9,3 & 10 & 9,3 & 4 & 8,0 & 4 & 5,3 & 4 & 4,8 & 4 & 4,8 \\
\hline $\begin{array}{l}\text { it gave the opportunity to use } \\
\text { the rules, operation, and } \\
\text { formulas }\end{array}$ & 5 & 6,5 & 5 & 6,5 & 2 & 1,9 & 7 & 6,5 & 2 & 2,7 & 8 & 10,7 & 2 & 2,4 & 5 & 6,0 \\
\hline $\begin{array}{l}\text { it shows tha conceptual } \\
\text { relations }\end{array}$ & 8 & 10,4 & 7 & 9,1 & 2 & 1,9 & 7 & 6,5 & 1 & 1,3 & 9 & 12,0 & 1 & 1,2 & 9 & 10,8 \\
\hline it was so easy & 8 & 10,4 & 5 & 6,5 & 5 & 4,6 & 7 & 6,5 & & & 1 & 1,3 & 1 & 1,2 & 4 & 4,8 \\
\hline $\begin{array}{l}\text { it was a question that only } \\
\text { those having the mathematical } \\
\text { knowledge and skills could } \\
\text { answer }\end{array}$ & 7 & 9,1 & 9 & 11,7 & 17 & 15,7 & 16 & 14,8 & 3 & 4,0 & 5 & 6,7 & 6 & 7,2 & 9 & 10,8 \\
\hline it looked familiar & 17 & 22,1 & 8 & 10,4 & 16 & 14,8 & 11 & 10,2 & 13 & 17,3 & 3 & 4,0 & 12 & 14,5 & 3 & 3,6 \\
\hline $\begin{array}{l}\text { the question let me make } \\
\text { revisions on it }\end{array}$ & 4 & 5,2 & 10 & 13,0 & 1 & 0,9 & 10 & 9,3 & 2 & 2,7 & 9 & 12,0 & 4 & 4,8 & 5 & 6,0 \\
\hline Other reasons & 2 & 2,6 & 1 & 1,3 & 2 & 1,9 & 1 & 0,9 & 2 & 2,7 & 1 & 1,3 & 1 & 1,2 & 2 & 2,4 \\
\hline
\end{tabular}

The Table 10 has given the reasons for why the ninth and tenth questions in the function test were answered by the students. When the data here is analyzed, the reasons of the students from all grades for responding to the ninth question are seen as mostly "because it looked familiar." This situation is an expected result for the ninth question. Indeed, this question is a question that the students always see and practice on as exercises. Also, the reasons of the students from all grades to have answered the tenth question appear to be mostly because "it was a question that only those having the mathematical knowledge and skills could answer" and "the question let me make revisions on it."

\section{DISCUSSION}

As a result of this research, it was realized that the students from all grades preferred, in terms of learning the function concept, those questions that hold the formalistic view values, relavance values, instrumental understanding/learning values, accessibility values, and reasoning values.

The findings of this research show some similarities and differences with the findings of a research that examines whether Seah and Bishop's (2000) Singapore and Victoria mathematics 
textbooks convey mathematics educational values or not. According to the research of Seah and Bishop, formalistic view, theoretical knowledge, instrumental understanding, specialism, and evaluating with larger emphases than their respective complementary values in both Singapore and Victoria mathematics textbooks. In present research, it is just seen that relavance, accessibility, and reasoning values towards the function concept are by students prefered more than complementary values as differences.

Moreover, the reasons of students for choosing particular questions in the function test are determined as because "it [a particular question] looked familiar," "it had a logic of induction," "it is related to daily life," "it only addresses to the theory," "it gave the opportunity to use the rules, operation, and formulas," "it shows tha conceptual relations," "it was so easy," and "it was a question that only those having mathematical knowledge and skills could do." This situation suggests that the students usually responded to the questions in the test by taking into consideration the mathematical educational values that they own. For instance, the fifth question has the instrumental understanding/learning value in math education, and the students responded to this question mostly because "it gave the opportunity to use the rules, operation, and formulas."

\section{Implications for Education}

In this research, the students were asked to answer five of ten open-ended questions relating to the function concept. In this way, it was intended to determine the selections of the students. The questions that the students preferred to answer on the test were, in an order, the seventh, first, tenth, ninth, sixth, fourth, second, third, and eight questions. The first five questions preferred have familiarity with the topics that the students studied in their maths textbooks and during the lessons. In addition, these questions generally reflect the abstract way of maths, its formalistic value. This fact illustrates that the students commonly hold the formalistic and theoretical values in maths. For this reason, the teachers need not only to bring to the fore not only the abstract way of topics and concepts that they are teaching in class but also to highlight their active and concrete values and their relevance to the real life.

\section{Implications for Mathematics Education}

Values are the crucial components of maths education. However, they are often neglected (Clarkson et al., 2000; Seah \& Bishop, 2000). Therefore, it is intended in this research to determine the values in maths education in terms of the students' mathematical comprehension of functions. In this way, the results of the research are of primary concern. As observed from the results of the research, the students often preferred the questions showing the symbolic aspect of the function concept. These students may be the teachers of the future. Naturally, they will 
convey their own mathematical education values to their students either explicitly or implicitly. In other words, it may be expected that they will focus in their proceeding education more on the mathematical values such as formalistic view, theoretical, and instrumental understanding/learning values. This partiality may lead to the fact that the students' maths education may be deprived of the values like activist, relevance, conceptual learning/understanding, and reasoning values. However, these values opportune the students to comprehend and relate maths to the outside world. In fact, NCTM standards cannot focus only on the problem-solving, mental computation, numerical logic. At the same time, they should focus on the students' being able to understand mathematical values, mathematical connections, and mathematical reasoning (Kathleen et al., 1993). Moreover, these standards are valid for other fields like science, chemistry, physics, and history. Hence, it is necessary that an education should be realized to discover the students' values in other classes too. For instance, science is not thought as having traditionally established values. But, science just like maths has values (Michael, 1995). Thus, for instance, the teaching of the slope concept in science should be taught by using the daily objects as well as the theoretical explanations. In this way, students will have possessed, in terms of the slope concept, the formalistic, activist, and relevance values.

\section{REFERENCES}

Beckmann, C., Thompson, D. and Senk, S. (1999). Assessing Students' Understanding of Functions in a Graphing Calculator Environment. School Science and Mathematics. December, 99, 8; ERIC, 451

Bishop, A. (1999). Mathematics Teaching and Values Education- An Intersection in Need of Research. Mathematics Teaching and Democratic Education. (Ed. Köhler, H.) Part 2. ZDM Analyses. Stuttgart.

Bishop, A. (2002). Research, policy and practice: The case of values. P. Valero \& O. Skovsmose (Eds.). Proceedings of the 3rd International MES Conference. Copenhagen: Centre for Research in Learning Mathematics, 1-7

Bishop, A., Clarkson, P., FitzSimons, G. and Seah, W.T. (2000). Why Study Values in Mathematics Teaching: Contextualising the VAMP Project. <www.education.monash.edu.au/projects/vamp/>, ( January 24, 2004).

Bishop, A., FitzSimons,G., Seah, W.T. \& Clarkson, P. (1999, December). Values in Mathematics Education: Making Values Teaching Explicit in the Mathematics Classroom. Paper Presented at the Combined Annual Meeting of the Australian Association for Research in Education and the New Zealand Association for Research in Education. Melbourne, Australia, November 29, December 2.

Brown, R. (2001). Educational Values and Summative Assessment A View Across Three Educational Systems. Paper presented at the Annual Conference of the Australian Association for Research in Education, Fremantle, Australia.

Cooney, T. (1999). Developing a Topic across the Curriculum: Functions. (Ed., Peake, L.) Mathematics, Pedagogy and Secondary Teacher Education. 361 Hannover Street, USA. 27-96. 
Chin, C., \& Lin, F.L. (2000). Values and values statement emerged in students preferences on test items: A Case Study from Mathematical Induction. In W.S. Horng, \& F.L. Lin (Eds.), Proceedings of the HPM 2000 Conference on History in Mathematics Education. Taipei, Taiwan: National Taiwan Normal University.

Clarkson, P., FitzSimons,G , Bishop, A.\& Seah, W. T. (2000, December). Methodology Challenges and Constraints in the Values and Mathematics Project. Paper Presented at the Annual Meeting of the Australian Association for Research in Education, Sydney, Australia, 4-7.

DeMarois, P.\& Tall,D. (1996). Facets and Layers of the Function Concept. Proceedings of PME 20, Valencia, 2, $297-304$. Dossey, J. (1999). Modeling with Functions. (Ed., Peake, L.) Mathematics, Pedagogy and Secondary Teacher Education. 361 Hannover Street, USA. 221-280.

Ernest, P. (1991). Mathematics, Values and Equal Opportunities. The Philosophy of Mathematics Education. The Falmer Pres, Taylor \& Francis Inc., 1900 Frost Road, Suite 101, Bristol, PA 19007, 259.

Eisenberg, T. (1991). Functions and Associated Learning Difficulties. Advanced Mathematical Thinking (Ed. Tall, D.). Kluwer Academic Publishers, Dordrecht, Boston, London.. 140-152.

Even, R. (1988, July). Pre-Service Teachers Conceptions of the Relationships Between Functions and Equations. PME XII., Hungary, 20-25.

FitzSimons, G. \& Seah, W.(2001, July). Beyond Numeracy: Values in the Mathematics Classroom. 24th Annual MERGA Conference, Sydney. (ERIC Document Reproduction Service No. ED 456047)

Gaea, L., Orit, Z. \& Kay. S. (1990). Functions, Graphs, and Graphing: Tasks, Learning, and Teaching. Review of Educational Research. 60(1), 1-64.

Hitt, F. (1998). Difficulties in the Articulation of Different Representations Linked to the Concept of Function. Journal of Mathematical Behavior, 17 (1), 123-134.

Hauge, S. (1993). Functions and Relations: Some Applications from Database Management for the Teaching of Classroom Mathematics. (ERIC Document Reproduction Service No. ED 365 51).

Kathleen, C. M. and Others (1993). The NCTM "Standards" : Implementation. Metropolitian Educational Researh Consortium, Richmond, VA:

Kieran, C. (1992). The Learning and Teaching of School Algebra. Handbook of Research on Mathematics Teaching and Learning. (Ed Grouws, D.).Macmillan Library Reference, New York, 390-419.

Kleiner, I. (1989). Evolution of the Function Concept: A Brief Survey. The College Mathematics Journal, 20 (4), 282-300.

Knuth, E. (2000). Understanding Connections between Equations and Graphs. The Mathematics Teacher, 93 (1), 48-53. Laughbaum, E. (2003). Developmental Algebra with Function as the Underlying Theme. Mathematics and Computer Education. 37 (1), 63-71.

Matthews, B.(2001). The Relationship between Values and Learning. International Education Journal. 2 (4). Educational Research Conference Special Issue. 223-232. 
Michael, P. (1995). Beliefs and Values and Science Education. Developing Science and Technology. Open University Press. Suite 101, 1900 Frost Road, Bristol.

Sam, L. \& Ernest, P. (1997, March). Values in Mathematics Education: What is Planned and What is Espoused? In Brirtish Society for Research into Learning Mathematics. Proceedings of the Day Conference held at University of Nottngham, 37-44.

Seah, W. T. (2002). Exploring Teacher Clarification Of Values Relating to Mathematics Education. In C. Vale \& J. Roumeliotis \& J. Horwood (Eds.), Valuing Mathematics in Society, 93-104. Brunswick, Australia: Mathematical Association of Victoria.

Seah, W. T. (2003). Understanding mathematics classroom experiences through the values lens. Paper presented at the Research Presession of the 81st Annual Meeting of the National, San Council of Teachers of Mathematics Antonio, TX. Seah, W. T. \& Bishop, A.J. (2000, April). Values in Mathematics Textbooks: A Wiew Throught The Australasian Regions. Paper Presented at the Annual Meeting of the American Educational Research Association, New Orleans, LA.

Seah, W. T. \& Bishop, A.J. (2002). Values, Mathematics and Society: Making The Connections. In C. Vale \& J. Roumeliotis \& J. Horwood (Eds.), Valuing mathematics in society (pp. 105-113). Brunswick, Australia: Mathematical Association of Victoria.

Stallings, L. (2000). A Brief History of Algebraic Notation. School Science and Mathematics, 100 (5), 230-235.

Sivas Municipality Activity Report. (1998). Sivas Municipality Activity Report of 1998. Esnaf Offset Publications, Sivas, Turkey.

Swadener, M. \& R. Soedjadi, R. (1988). Values, Mathematics Education and the Task Of Developing Pupils' Personalities: An Indonesian Perspective, Educational Studies In Mathematics. 19 (2), 193-208.

Tall, D. (1992). The Transition to Advanced Mathematical Thinking: Functions, Limits, Infinity, and Proof. (Ed. Grouws, D). Handbook Of Research On Mathematics Teaching And Learning. Macmillan Library Reference, New York, 495-510.

Tall, D.\& Vinner, S. (1981). Concept Image and Concept Definition in Mathematics with particular reference to Limits and Continuity. Educational Studies in Mathematics, 12, 151-169.

Tavşancıl, E. (2002). Measurement of Aptitudes and Data Analysis with SPSS. Nobel Publications. Ankara.

\section{Yüksel Dede}

Cumhuriyet University, Education Faculty, Department of Mathematics Education

Sivas, Turkey

E-mail: ydede@cumhuriyet.edu.tr

Phone: (+ 90 346) $2191010 / 2261$

Fax: (+ 90346$) 2191224$ 